\title{
Body of Graft
}

National Cancer Institute

\section{Source}

National Cancer Institute. Body of Graft. NCI Thesaurus. Code C99918.

The portion of the graft that lies between its anastomoses. (ACC) 